\title{
Stages of Change, Self-efficacy and Stress Management Perceptions in First Year Undergraduate Students
}

\author{
Karagiannopoulou Evangelia, Kamtsios Spiridon*
}

Department of Philosophy, Education and Psychology, Section: Psychology,University of Ioannina, Greece

\begin{abstract}
The study explored first year undergraduate students' intention to change behavior in an attempt to manage stressful academic situations (passing the exams, semester's grades and organization of their studies) and the effect of the self-efficacy, the pros, cons of stress management and the pros of stress on moving between stages. Gender differences were explored. The validity and reliability of the Decision Balance Inventory were also investigated. The study was held through questionnaires. All scales had acceptable levels of internal consistency $(60<\alpha<79)$ and the sample consisted of 209 first-year undergraduate students. The results of the exploratory factor analysis supported the factorial validity and the reliability of the Decisional Balance Inventory. Most of the students reported themselves in the earlier stages of change. The results indicated an interplay of self-efficacy with the pros, cons of stress management and the pros of stress, mainly at the stages of precontemplation and preparation. There were few gender differences. Females reported a less positive perception of the pros of stress management than males when closer to adopt a behavior of stress management. The findings are discussed in relation to recent literature.
\end{abstract}

Keywords Stages of Change, Transtheoretical Model of Change, Self-Efficacy, Stress

\section{Introduction}

The importance of stress as a public health issue is widely recognised, as stress and stress-related health problems constitute important issues handled by today's society. According to Lazarus and Folkman (1984)[1], psychological stress is a particular relationship between the person and the environment that is appraised by the person as taxing or exceeding his or her resources and endangering his or her well-being. Stress has been explored with reference to different situations (e.g. life events), in different age groups and social groups (e.g. executives, health care professionals, groups with disabilities and their families)[2,3].

Research has recognized the impact of stress-related emotional status on college students. Attending university presents students with learning opportunities and opportunities for psychological development[4]. However, entering university may be a source of strain and an acute stressor[5] because academic demands increase and new social relations are established[4]. Researchers report a number of academic, financial and lifestyle stressors that represent chronic sources of stress[6] in students' life, such as their daily relationships, their future business anticipation, family problems and stressors about their studies (organization and

* Corresponding author:

spiroskam@gmail.com (Spiros Kamtsios)

Published online at http://journal.sapub.org/ijpbs

Copyright (C) 2011 Scientific \& Academic Publishing. All Rights Reserved quality)[7-10]. Makrides, Veinot, Richard, McKee, \& Gallivan (1998)[11], reported that the 60 per cent of the college students rated their stress levels for academic issues as high or very high. Polychronopoulou and Divaris (2005)[12], mention that the pressure to perform well in the examination or test and time allocated makes academic environment very stressful. Also, Campel, Svenson \& Jarvis (1992)[13], found that undergraduate women who were asked how they perceived their stress level, reported that they experienced unacceptable levels of stress for their studies, especially for their semester course grades. A range of studies reported that females perceived more stress in the university environment than their males' counterparts and they used more emotion oriented coping strategies[14,15].

Individuals have resources to cope with stressful situations. Successful coping implies learning to activate these resources. In other words, going from overwhelming stress-to-stress management is an active process implying change[16], which can be described through the Transtheoretical Model of Change (TTM)[17]. The TTM is a theoretical and integrative model of behavior change, which has been the basis for developing effective interventions to promote health behavior change. The model describes how people modify a problem behavior or acquire a positive behavior. The model has been applied to a wide variety of problem behaviors. These include smoking cessation, exercise, low fat diet, alcohol abuse, weight control, condom use for HIV protection, organizational change, use of sun screens to prevent skin cancer, drug abuse, medical com 
pliance, mammography screening, and stress managemen[17].

The central organizing construct of the model is the stages of change, reflecting intentional change. Behavior change was often construed as an event, requires change as a process through a series of five stages[17]. In the TTM[18] the stages of change dimension reflect a person's readiness to change behavior, or the engagement in behavior change, at a given point in time. The stages of change hypothesize that individuals move cyclically through the following six stages, with periods of progression and relapse. The first two stages represent people who are least ready to change (precontemplation) or are ambivalent about change (contemplation); the third stage represents people who are preparing to change in the next month (preparation); the last two stages represent active behavior change if the change is recent (action), or sustained behavior change if the change has been maintained for more than 6 months (maintenance). Finally, individuals are said to be in the termination stage when they have maintained the specific behavior for more than five years and have $0 \%$ temptation to engage in the undesired behavior and $100 \%$ self-efficacy to engage in the desired behavior[19]. Movement through the stages is fluid and cyclical as people try to change their behaviour[17-19].

The application of the TTM on stress and stress management has been suggested as complicated and obscure and thus few studies have been published so far[17,20-23]. The primary focus of these studies has been to examine the feasibility of applying the TTM to this area and developing and validating measures of the key TTM constructs[24]. These studies have been conducted with a variety of populations including students, work site samples, random digit dialling samples and women who are infected with HIV[17,21]. A major difficulty is participants' experience and conceptualization of the concept of stress and participants' awareness of the stressful situations. Coping with stress, as a behavior, is not as concrete and measurable as other forms of behaviors, like smoking cessation[16] or physical activity participation[25]. Evers and his colleagues (2006)[22], overcome this difficulty by providing the participants with a particular definition of stress management, on the basis of which they are asked to answer the inventory they are given: "stress management includes regular relaxation and physical activity, talking with others, and/or making time for social activities". This approach focuses more on "effectively managing stress" in which typical stress management behaviors and activities are provided to assist individuals in accurately assessing their own stress management levels[24].

A number of studies[26-30] have mentioned that the model rounds off theoretically with the self-efficacy concept, the decisional balance measures of the positive (pros) and negative (cons) of adopting effective stress management practices and ten processes of change (five experiential and five behavioral) for progressing to the action and maintenance stages. These concern: consciousness raising, dramatic relief, environmental re-evaluation, self re-evaluation, social liberation, counter conditioning, helping relationships, reinforcement management, self liberation and stimulus control.

Self-efficacy, originally a construct in social learning theory[31] (is the situation-specific confidence to overcome a high risk circumstance without relapse into an unhealthy habit[32]), was added to the TTM[33] to help predicting stages of change. Individuals with low self-efficacy, i.e., little confidence that they can perform the desired behavior in a high-risk situation, would more likely be in the earlier stages of change. A range of questionnaires has been developed to assess self-efficacy in different situations; e.g. the self-efficacy scale about performing tasks involved in consuming the recommended numbers of servings of fruits and vegetables[28] the self-efficacy for exercise scale[34] the self-efficacy scale, for expectations to quit smoking[35] and the self-efficacy scale for stress management, that assesses individuals' confidence in their ability to manage stress in academic stressful situations[36].

Besides, decisional balance i.e. the positive (pros) and the negative (cons) factors associated with stress management was added to the stages of change model to explain the variability in stages[18,29]. For progression through the stages, the pros of stress management behavior or attitude change must increase to move out of precontemplation, the cons must decrease to move out of contemplation, and, to move into action, the absolute number of pros has to be more than the number of cons[18].

The present study aims to explore (a) students' intention to change behavior in an attempt to manage stressful academic situations (e.g. passing the exams, semester's grades, organization of their studies) (b) whether the relation between students' self-efficacy and their perception of the pros, cons of stress management as well as the pros of stress varies between males and females among the stages of change in which students reported themselves (c) to investigate the validity and reliability of the "Decisional Balance Inventory for Stress Management" in a Greek sample.

\section{Methodology}

\section{Participants and study design}

Two hundred and nine (209) first year undergraduate social science students participated in this study, aged 18 to 21 years ${ }^{1}$. Data collection was carried out in the end of the second semester. Questionnaires were administered to students at the end of the lectures. Before completing the questionnaires, students were presented with the aims of the study. It was pointed out that participation was voluntary and anonymous. All subjects were assured that their answers would have no effect on their grade in the class. Next, instructions about how to complete the questionnaires were read out.

\section{Measures}


Before answering the 1,2 and 3 scales, students were asked to answer an open-ended question concerning the most stressful situations during their studies. Answers were reported in hierarchical order. Students were then asked to complete the "Stages of change for stress management questionnaire", the "Decisional balance inventory for stress management" and the "self-efficacy scale" on the basis of the stressor they reported as the most significant for them.

1. Stages of change for stress management questionnaire[22]. Participants were given the following definition of stress management: Stress management includes regular relaxation and physical activity, talking with others, and/or making time for social activities[17]. They were then asked, "Do you effectively practice stress management in your daily life concerning the situation you reported above as the most stressful one in the hierarchy?" Five response categories were available, placing the participants in one of five stages of change for stress management: precontemplation (not intending to begin in the next 6 months), contemplation (intending to begin in the next 6 months), preparation (intending to begin in the next 30 days), action (practicing the behavior, but for less than 6 months) or maintenance (practicing the behavior for at least 6 months)[22]. The termination stage was not taken into account in the current study because it concerns maintenance of a specific behaviour for more than 5 years (students usually complete their studies in four years).

2. Decisional Balance Inventory for Stress Management. This scale was initially developed by Fava, Norman \& Levesque (1998)[37]. A decade later it was reconstructed and further developed by Dye, Redding, Fava, Rossi, Robbins, Meir, Velicer \& Prochaska (2007)[38]. The recent version of the inventory (with three factors and 15 items) was used after having contact with the researchers who allowed us access to the key of the scale and the pattern of the analysis of the data. Dye et al. (2007)[38]tested the questionnaire with consecutive confirmatory factor analyses. They reported accepted to high alpha Cronbach coefficients for all of the factors (.82 for the pros of stress management - five items, .72 for the cons of stress management - five items and .69 for the pros of stress - five items). Answers are given in a 5-point Likert scale (ranged from 1 to 5).

3. A self-efficacy 10-item scale adapted to stress by Schwarzer $(1993,1995)[36,39]$ was used in the present study. This scale was used because it was oriented to participants' efforts to manage stressful academic situations. Participants had to answer on a three-point scale if they were (1) very confident, (2) a little confident, or (3) not at all confident to manage their stress in specific situations (e.g. are you confident to be able to manage stressful academic situations when...you have personal problems?...you feel angry?...you are under time pressure?...you are tired?...you have insomnia?...you are frustrated (disappointed)?...you feel afraid?...you have difficulties to stop a habit (e.g. smoking)?...you feel sad?...you thing about mistakes or things you did wrong?). The mean score of the 10 items was calculated for each respondent. This stands for the respondents' self-efficacy score. Schwarzer (1993)[36] reported a high Cronbach's alpha coefficient (.81). In a recent study with Greek undergraduate students the researchers Cronbach's alpha coefficient of the scale appeared accepted, not high (.69)[40].

The reverse translation method was used to get the Greek version of the scales reported above (Stages of change for stress management questionnaire, Decisional Balance Inventory for Stress Management and Self-efficacy).

\section{Statistics}

The Statistical Package for the Social Sciences (SPSS, version 11.0) software was used for all statistical calculations. Descriptive statistics were used for the means and standard deviations of the scales. The Chi-square test was used to examine gender differences in the number of students (males \& females) in each stage of change for stress management. Exploratory factor analysis was used to examine the construct validity of the Decisional Balance Inventory for Stress Management. Internal consistency was tested with the alpha reliability test[41] and the split-half test. To examine the linear relationships between the variables, the Pearson correlation coefficient was used. Differences in the pros, cons of stress management, cons of stress and self-efficacy at different stages of change were tested by the two-way Anova statistical test. Also, gender differences were explored with the same statistical test. Comparisons were considered as significant at a $P$-value of 0.05 or less.

\section{Results}

\section{Open-ended Question and Descriptive Statistics}

Table 1 is a frequency table that illustrates situations reported by students as stressful. Academic stressors (e.g. passing the exams, semester's grades, organization of their studies) were reported as the most detrimental by two hundred and nine (209) (86 males and 123 females) undergraduate students. Interestingly, the third stressor appears to concern issues about the future occupational life, which to some extent may be related to academic issues.

Table 1. Stressors reported by students as the most significant.

\begin{tabular}{ccc}
\hline Events that cause stressful situations & $\mathrm{N}$ & $\%$ \\
\hline Academic issues & 209 & $41.2 \%$ \\
Personal problems & 83 & $16.5 \%$ \\
Future occupational life & 65 & $12.7 \%$ \\
Relationships with partners & 49 & $9.7 \%$ \\
Economics & 45 & $8.7 \%$ \\
Health problems & 31 & $6.2 \%$ \\
Relationships with friends & 18 & $3.6 \%$ \\
Death of a parent, friend or relative & 7 & $1.4 \%$ \\
\hline
\end{tabular}

Table 2 depicts the number of students at each stage of change. Most of them reported themselves in the first stage of change (precontemplation, contemplation and preparation), fewer in the next stages (action and maintenance) and only five students in the termination stage. These students were excluded from the data set. The termination stage is 
not included in the statistical analysis presented below. The Chi-square statistical test revealed statistically significant differences in the number of undergraduate males and females in the stages of preparation and action $\left(\mathrm{x}_{(4)}^{2}=16.87\right.$, $\mathrm{p}=.005)$. Table 2 indicates that more females than males reported themselves at the stages of preparation and action.

Table 2. Number of students in each stage of change for stress management.

\begin{tabular}{|c|c|c|c|}
\hline Stages of change & n & Male & Female \\
\hline Precontemplation & 32 & 19 & 13 \\
\hline Contemplation & 53 & 25 & 28 \\
\hline Preparation & 53 & 17 & 36 \\
\hline Action & 38 & 8 & 30 \\
\hline Maintenance & 33 & 18 & 15 \\
\hline
\end{tabular}

Factor analysis

A principal components analysis with varimax rotation was performed for the Decisional Balance Inventory for Stress Management. The researchers used principal component analysis (the most commonly used version of factor analysis), to identify the rotated factor pattern of the inventory independent scales in order to get the factors with the clearest structure, which makes easy investment with psychological meaning. Concerning the overall sample $(\mathrm{N}=209)$ factor analysis of the independent scales produced a three-factor solution (based on eigenvalues and the scree plot), which extracted $55.19 \%$ of the total variance. The minimum loading used to identify items to factors was .30 .
The factor pattern matrix of loadings is shown in Table 3. In the Greek sample, all the three factors consist of four items. The first factor, "pros of stress management", accounted for $22.35 \%$ of the total variance. The second factor, "pros of stress", accounted for $17.78 \%$ of the total variance and the third factor, "cons of stress management", for $15.06 \%$ of the total variance. Internal consistency was satisfactory. The Cronbach's alpha reliability coefficients for the Decisional Balance Inventory for Stress Management were .71. The Cronbach's alpha coefficients for the factors (Table 4) were ranged from .60 to .76 .

Correlation analysis of the three factors revealed a positive low correlation $(.21<. r<.34)$, indicating the independence of the factors.

After the above analyses, scale scores were calculated for each of the three factors of the Decisional Balance Inventory for Stress Management and the self-efficacy scale. The Anova two-way statistical test was followed by the sidak post hoc test (sidak was used to compare variables from different data collection) to explore differences in the pros, cons and pros of stress management reported by students at different stages of change. The same statistical test was used to identify gender differences among the five stages of change. Effect sizes $\left(n^{2}-\right.$ i.e. proportion of the total variance that is attributed to an effect) were calculated to assess the significance of the differences between the stages.

Table 3. Component loadings associated with the principal components analyses for the Decisional Balance Inventory for Stress Management. Results are presented in comparison to that reported by Dye et al. (2007).

\begin{tabular}{|c|c|c|c|c|c|c|c|}
\hline & \multirow{2}{*}{ Items } & \multicolumn{3}{|c|}{ Loadings (Greek sample) } & \multicolumn{3}{|c|}{ Loadings (Dye et al. (2007) } \\
\hline & & 1 & 2 & 3 & 1 & 2 & 3 \\
\hline 1 & Relationships with others would improve if I could manage my stress & .89 & & & .81 & & \\
\hline 7 & I would be a more pleasant person if I manage the stress in my life & .79 & & & .49 & & \\
\hline 10 & Others close to me suffer when I am stressed & .62 & & & .77 & & \\
\hline 4 & $\begin{array}{l}\text { Managing my stress would allow me to be more effective in working } \\
\text { toward important goals. }\end{array}$ & .55 & & & .80 & & \\
\hline 9 & I get more done when I am stressed & & .84 & & & .85 & \\
\hline 12 & Feeling stressed is the only way I meet my deadlines & & .65 & & & .64 & \\
\hline 6 & Stress helps me to concentrate and do better work & & .63 & & & .94 & \\
\hline 3 & Enjoy a driven lifestyle & & 60 & & & .94 & \\
\hline 5 & Efforts to manage stress would be disruptive to daily life & & & .78 & & & .83 \\
\hline 11 & Managing stress would be a hassle & & & .64 & & & .75 \\
\hline 8 & I would be ashamed to seek help from others to manage my stress & & & .63 & & & .74 \\
\hline 2 & Managing stress would take too much time & & & .37 & & & .90 \\
\hline & $\%$ of the variance & 22.35 & 17.78 & 15.06 & & & \\
\hline & Eigenvalues & 2.9 & 2.3 & 1.95 & & & \\
\hline & K.M.O. $=.70$ & & & & & & \\
\hline & Bartlerr Test of Sphericity $=836.58, \mathrm{p}=.000$ & & & & & & \\
\hline
\end{tabular}

Factor 1: Pros of stress management

Factor 2: Pros of stress.

Factor 3: Cons of stress management

Table 4. Split half and Cronbach alpha reliability coefficients of the factors in the Decisional Balance Inventory for Stress Management, and the self-efficacy scale.

\begin{tabular}{lccc}
\hline & Number of questions & Split half & Alpha \\
\hline Prons of stress management & 4 & .73 & .79 \\
Cons of stress management & 4 & .50 & .60 \\
Pros of stress & 4 & .69 & .66 \\
Self efficacy & 10 & .66 & .66 \\
\hline
\end{tabular}


Table 5. Means and standard deviations of the pros, cons of stress management, pros of stress and self-efficacy reported by students in different stages of change.

\begin{tabular}{cccccc}
\hline & & \multicolumn{3}{c}{ Stages of change } & \\
& precontemplation & Contemplation & preparation & action & maintenance \\
& $\mathrm{M}[\mathrm{sd}]$ & $\mathrm{M}[\mathrm{sd}]$ & $\mathrm{M}[\mathrm{sd}]$ & $\mathrm{M}[\mathrm{sd}]$ & $\mathrm{M}[\mathrm{sd}]$ \\
\hline pros of stress management & $3.37[.82]^{1}$ & $3.4[.98]$ & $3.9[.89]$ & $4.00[.79]^{1}$ & $3.51[.85]$ \\
cons of stress management & $2.66[.69]$ & $2.8[.75]$ & $2.521 .01]$ & $2.84[.79]$ & $2.63[.82]$ \\
pros of stress & $1.78[1.02]^{2}$ & $1.79[.68]^{3}$ & $3.16[.87]^{2,3}$ & $2.38[.72]$ & $2.44 .86]$ \\
Self-efficacy & $1.67[.31]^{4,5}$ & $1.71[.31]$ & $1.72[.38]$ & $1.79[.31]^{4}$ & $1.74[.34]^{5}$ \\
\hline
\end{tabular}

$1=$ Differences between precontemplation and action stage for the pros of stress management

$2=$ Differences between precontemplation and preparation stage for the pros of stress.

$3=$ Differences between contemplation and preparation stage for the pros of stress

$4=$ Differences between precontemplation and action stage for the self-efficacy

$5=$ Differences between precontemplation and maintenance stage for the self-efficacy

Table 6. Gender differences between the stages of change.

\begin{tabular}{|c|c|c|c|c|c|c|c|c|c|c|}
\hline & \multicolumn{2}{|c|}{ precontemplation } & \multicolumn{3}{|c|}{ contemplation } & \multirow{3}{*}{$\begin{array}{c}\text { preparation } \\
\text { female } \\
\mathrm{M}[\mathrm{sd}]\end{array}$} & \multirow{3}{*}{$\begin{array}{l}\text { action } \\
\text { male } \\
\mathrm{M}[\mathrm{sd}]\end{array}$} & \multicolumn{3}{|c|}{ maintenance } \\
\hline & male & female & male & female & male & & & female & male & female \\
\hline & $\mathrm{M}$ [sd] & $\mathrm{M}[\mathrm{sd}]$ & $\mathrm{M}[\mathrm{sd}]$ & $\mathrm{M}$ [sd] & $\mathrm{M}$ [sd] & & & $\mathrm{M}$ [sd] & $\mathrm{M}$ [sd] & $\mathrm{M}[\mathrm{sd}]$ \\
\hline $\begin{array}{l}\text { pros of stress } \\
\text { management }\end{array}$ & $3.52[.09]$ & $3.43[.08]$ & $2.3[.30]^{2}$ & $4.0[.22]^{2}$ & $4.45[.26]^{1}$ & $2.8[.37]^{1}$ & $4.8[.53]$ & $3.6[.33]$ & $3.52[.26]$ & $3.5[.14]$ \\
\hline $\begin{array}{l}\text { cons of stress } \\
\text { management }\end{array}$ & $2.665[.83]$ & $2.66[.38]$ & $3.33[.73]^{3}$ & $2.51[.62]^{3}$ & $1.33[.00]^{4}$ & $3.00[.74]^{4}$ & $2.91[1.17]$ & $2.82[.68]$ & $2.62[.94]$ & $2.63[.72]$ \\
\hline pros of stress & $1[.0]$ & $2.1[1.06]$ & $1.87[.13]$ & $1.75[.85]$ & $3.0[.98]$ & $3.5[.57]$ & $2.46[.52]$ & $2.35[.78]$ & $2.63[.87]$ & $2.28[.82]$ \\
\hline Self-efficacy & $1.63[.33]$ & $1.71[.34]$ & $1.66[.33]$ & $1.80[.27]$ & $1.75[.49]$ & $1.71[.32]$ & $1.71[.44]$ & $1.81[.77]$ & $1.71[.32]$ & $1.78[.36]$ \\
\hline
\end{tabular}

$1=$ gender differences in the preparation stage for the pros of stress management

$2=$ gender differences in the contemplation stage for the pros of stress management

$3=$ gender differences in the contemplation stage for the cons of stress management

$4=$ gender differences in the preparation stage for the cons of stress management

Table 7. Correlations between the self-efficacy and the pros of stress management, cons of stress management and the pros of stress reported by males and females participants in different stages of change.

\begin{tabular}{|c|c|c|c|c|c|c|c|c|c|c|c|c|c|c|c|}
\hline & \multicolumn{15}{|c|}{ Stages of change } \\
\hline & \multicolumn{3}{|c|}{ Precontemplation } & \multicolumn{3}{|c|}{ Contempation } & \multicolumn{3}{|c|}{ Preparation } & \multicolumn{3}{|c|}{ Action } & \multicolumn{3}{|c|}{ Maintenance } \\
\hline & $\begin{array}{c}\text { Total } \\
\text { sam- } \\
\text { ple }\end{array}$ & $\begin{array}{c}\text { Mal } \\
\mathrm{e}\end{array}$ & $\begin{array}{c}\mathrm{Fe}- \\
\text { male }\end{array}$ & $\begin{array}{c}\text { Total } \\
\text { sam- } \\
\text { ple }\end{array}$ & $\begin{array}{c}\text { Mal } \\
\mathrm{e}\end{array}$ & $\begin{array}{l}\mathrm{Fe}- \\
\text { male }\end{array}$ & $\begin{array}{c}\text { Total } \\
\text { sam- } \\
\text { ple }\end{array}$ & $\begin{array}{c}\text { Mal } \\
\mathrm{e}\end{array}$ & $\begin{array}{l}\mathrm{Fe}- \\
\text { male }\end{array}$ & $\begin{array}{l}\text { Total } \\
\text { sam- } \\
\text { ple }\end{array}$ & $\begin{array}{c}\text { Mal } \\
\mathrm{e}\end{array}$ & $\begin{array}{l}\text { Fe- } \\
\text { male }\end{array}$ & $\begin{array}{c}\text { Total } \\
\text { sam- } \\
\text { ple }\end{array}$ & $\begin{array}{l}\text { Mal } \\
\mathrm{e}\end{array}$ & $\begin{array}{l}\mathrm{Fe}- \\
\text { male }\end{array}$ \\
\hline $\begin{array}{c}\text { Pros of } \\
\text { stress } \\
\text { manage- } \\
\text { ment }\end{array}$ & $.60 * *$ & -96 & .09 & .13 & .67 & .-09 & .25 & .25 & .18 & .35 & .48 & .31 & .18 & .15 & .22 \\
\hline $\begin{array}{l}\text { Cons of } \\
\text { stress } \\
\text { manage- } \\
\text { ment }\end{array}$ & $-63^{*}$ & -67 & -60 & -40 &.-70 &.-45 & -95 & $\begin{array}{l}.-5 \\
2\end{array}$ &.-22 &.-39 &.-24 &.-34 &.-09 & .05 &.-17 \\
\hline $\begin{array}{c}\begin{array}{c}\text { Pros of } \\
\text { stres }\end{array} \\
\end{array}$ & $.68 * *$ & .60 & .32 &.-09 &.-27 & .08 & .89 & .37 & .39 &.-15 & $\begin{array}{l}.-4 \\
1 \\
\end{array}$ & -07 & .19 & .26 & .21 \\
\hline
\end{tabular}

** Correlation is significant at the 0.001 level

*Correlation is significant at the 0.05 level.

The mean scores presented in Table 5, indicate that students at the stage of precontemplation scored lower on the pros of stress management than those at the stage of action $\left[\mathrm{F}_{(5,198)}=2.32, \mathrm{p}<.05, \mathrm{n}^{2}=.046\right]$. Also, both students at the stage of precontemplation $\left[\mathrm{F}_{(5,198)}=6.48, \mathrm{p}<.05, \mathrm{n}^{2}=.119\right]$, and contemplation $\left[\mathrm{F}_{(5,198)}=5.91, \mathrm{p}<.05, \mathrm{n}^{2}=.095\right]$ scored lower on the pros of stress those at the stage of preparation.

The two-way Anova statistical test was also used to identify differences in self-efficacy reported by males $\&$ females at different stages of change. Table 5 indicates that students at the stage of precontemplation scored lower in self- effi-

cacy compared to those at the stage of action and those at the stage of maintenance $\left[\mathrm{F}_{(5,198)}=3.80, \mathrm{p}<.05, \mathrm{n}^{2}=.093\right]$

The two-way Anova indicates few gender differences inn the pros, cons and pros of stress management in different stages of change (Table 6). At the stage of contemplation females scored higher than males on the pros of stress management $\left[\mathrm{F}_{(5,198)}=19.90, \mathrm{p}=.000, \mathrm{n}^{2}=.094\right]$ and males scored higher on the cons of stress management $\left[\mathrm{F}_{(5,198)}\right.$ $\left.=4.00, \mathrm{p}=.047, \mathrm{n}^{2}=.020\right]$. The reverse was the case at the stage of preparation where males scored higher than females on the pros of stress management $\left[\mathrm{F}_{(5,198)}=12.87\right.$, 
$\left.\mathrm{p}=.000, \mathrm{n}^{2}=.063\right]$ and females scored higher on the cons of stress management $\left[\mathrm{F}_{(5,198)}=6.10, \mathrm{p}=.014, \mathrm{n}^{2}=.031\right]$.

Correlations

Table 7 indicates that most of the significant correlations between self-efficacy and the Decisional Balance Inventory for Stress Management appear at the stage of precontemplation; there were also few at the stage of preparation. Most of them concern the overall sample and the male sample. In both stages the pros of stress were highly correlated with the self-efficacy reported by the whole sample. Besides, the cons of stress management were significantly correlated in a negative way with the self-efficacy in most of the stages of change.

In particular, at the stage of precontemplation, all of the three factors included in the Decisional Balance Inventory for Stress Management (pros and cons of stress management and pros of stress) were highly correlated with the self-efficacy reported by the whole sample and the male students. Concerning the female sample, only the cons of stress management were negatively correlated with the self-efficacy.

Concerning the contemplation stage, there were only few significant correlations. Males reported high positive and negative significant correlations respectively of the pros of stress management and the cons of stress management with self-efficacy.

Concerning the stage of preparation, the pros of stress were highly correlated with self-efficacy reported by both the males and the females and also by the whole sample. The cons of stress management were very highly correlated in a negative way with the self-efficacy reported by the whole sample. These correlations were lower for the male sample.

Concerning the action and the maintenance stages, there were few and quite low correlations comparing to those reported at previous stages (Table 7). At the action stage, the cons of stress management were negatively correlated with the self-efficacy reported by the whole sample. Concerning the males, there was a positive correlation of the pros of stress management with the self-efficacy. At the maintenance stage there was only a very low positive correlation between the pros of stress management and self-efficacy reported by the whole sample.

\section{Discussion}

The study examines the relation between the stages of change for stress management and perceptions of the pros and cons of stress management and self-efficacy concerning stress management reported by first year undergraduate students. The study only partially supports previous findings that self-efficacy increases among the stages of change up to the stage of maintenance. It is indicated that the self-efficacy appeared to interplay with the pros, cons of stress management and the pros of stress mainly at the stages of precontemplation and preparation rather than at any other stage. There were few gender differences. Females reported a less positive perception of the pros of stress management than males when closer to adopt a behavior of stress management.

Regarding students' intention to change behavior, it has been found that most of them report themselves in the first stages of change (precontemplation: 29 students, contemplation: 52 students, preparation: 52 students). This may indicate either a lack of intention to change behavior or a positive intention, which is no guarantee for behavior change[42]. Perhaps, the big number of students in the stage of contemplation and preparation reflects that many first year students are ambivalent or think about changing behavior but do not get into action. As newcomers, they may feel unfamiliar with the new academic demands and uncertain of their abilities to meet them[43]. However, some students, mainly females reported themselves in later stages; action (38 students) and maintenance (33 students). Also, more females than males appear to report themselves at the stage of preparation indicating intention to change behavior. These findings may indicate that the strategies explored in the present study concerning regular relaxation and physical activity, talking with others, and/or making time for social activities are mainly employed by females, to cope with academic stress. This seems to be in line with previous studies suggesting that females prefer avoidance cognitive strategies[44,45].

The study indicates good psychometric properties for the "Decisional balance inventory for stress management". The exploratory factor analysis suggests three independent factors, which are identical to the ones suggested by Dye et al. (2007)[38]. These accounted for the 55.19\% of the total variance. The reliability coefficients were ranged from accepted to high. The factor "pros of stress management" gives the higher Cronbach alpha score. This is in line with the Dye et al (2007)[38] study. Although a confirmatory factor analysis could be used instead of the exploratory factor analysis employed in the present study, the exploratory factor analysis has been suggested as the most appropriate analysis at the first stage of the exploration of the validity of questionnaires[46] transferred to different populations. Future research with larger samples employing confirmatory factor analysis would provide useful information about the generalizability of the present factor structure and may shed light on the validity of the questionnaire.

Not surprisingly, students at the stage of action reported a more positive perception of the pros of stress management comparing to those at the stage of precontemplation, indicating a positive perception of managing academic stress in their lives. Similarly, students who are about to engage particular behaviors (stage of preparations) for academic stress management appear to perceive in a positive way the stress itself. This possibly indicates that they perceive the academic stressful situations as a challenge, which increases their effort and leads to deep involvement with the task at 
hand.

The study only partially supports previous findings indicating that students' self-efficacy concerning the stress management varies between stages from lower to higher. The lower score on the self-efficacy scale reported by students at the stage of precontemplation comparing to that reported by their counterparts at the stages of action and maintenance support previous studies[47,27] indicating that individuals at the stage of precontemplation score lower in self-efficacy comparing to those at the stage of maintenance. However, the present study does not indicate consistent increase of students' self-efficacy among the stages. This may imply that instant measures of self-efficacy are inappropriate to provide an "objective" measure of an individual's self-efficacy[48]. Particularly, in the present study first-year students are highly likely to feel uncertain of their ability to cope with the new academic demands[43]. Besides, lack of significant differences in self-efficacy reported by students at later stages of change (action and maintenance) is supported by previous studies indicating that self-efficacy is a less significant moderator variable in these stages[49] since individuals who have already employed a specific behavior are not likely to abandon this behavior, at least in the near future.

Concerning the second aim of the study, it is indicated that when females are closer to involve themselves into action (preparation and action stage), they perceive in a more negative way the stress management (higher scores on the cons) than their male counterparts, while in earlier stages they score higher on the pros. Perhaps this finding is supported by studies indicating that females usually report higher overall level of stress[15] comparing to their male counterparts. Their negative perception of stress management when they get into later stages of change may be related to their belief that the situations they cope with are not within their control[44]. Such a belief may lead them to the employment of avoidance strategies (employ behaviors of regular relaxation, physical activity, talking with others and making time for social activities), explored in the present study, to reduce stress.

Previous findings indicate that female college students use higher levels of emotion-focused coping strategies[14]. Concerning the males, those at the stage of preparation (thinking about getting into action), appears to perceive in a less negative way the cons of stress management and in a more positive way the pros of stress management. However, not many get into the action stage. In line with the above suggestions, males possibly prefer fight-oriented techniques to cope with academic stress and may want to be confident about the positive impact of the stress management on their lives to decide changing behavior.

This last suggestion about males' need to be confident about the cons of stress management as they get closer to change behavior is supported by the high negative correlation between the cons of stress management and self-efficacy reported by males at the stage of preparation and also by the high positive correlation between the self-efficacy and the pros of stress reported at the stage of action. Self-efficacy does not seem to play a crucial role in the females' decision to employ these copying strategies. None of the correlations between self-efficacy and the factors in the decisional balance inventory was significant in the relevant stages. Overall, females reported very few significant correlations between the variables in the Decisional Balance Inventory and self-efficacy. Perhaps, this is related to the particular strategies explored in the present study, which are oriented to reduce stress. Previous studies indicate that females usually employ more maladaptive coping strategies, which can be explained by the use of emotionally attentive or ruminative strategies[45].

Concerning the male sample, the study indicates that by vitalizing self-efficacy, emphasizing the pros and decreasing the cons for stress management, undergraduates may be able to change their behavior moving through the stages, to cope successfully with academic stress. However, this did not appear to be the case for the females. Future research on the stages of change may take into account gender as a moderator variable that must be considered when developing and implementing behavior change strategies.

The focus of the study on stress management by the use of "avoidance-oriented" strategies may be a limitation of the present study. Future research needs to focus on fight coping strategies. Furthermore, the use of qualitative methodology for the exploration of gender differences may shed light on our understanding of how gender mediates stress management leading to change behavior. It would be useful for our understanding of the feasibility of applying the TTM model to students' stress, future studies to investigate the interplay of the variables included in the present study in a larger sample consisting of students in different years of studying. This may provide valuable information for the development of an intervention model of stress management in student population.

\section{REFERENCES}

[1] R., S., Lazarus, S., Folkman, 1984. Stress, appraisal and coping, New York: Springer

[2] Edward, D., Burnar, P., 2003, A systematic review of stress and stress management interventions for mental health nurses Journal of Advanced Nursing, 42(2), 169-200

[3] Tekinalp, B., Akkok, F., 2004, The effects of a coping skills training program on the coping skills, hopelessness and stress levels of mothers of children with autism, International Journal for the Advancement of Counselling, 26(3), 257-269

[4] Tao, S., Dong, Q., Pratt, M., Husberger, B., Pancer, M., 2000, Social support: Relations to coping and adjustment during the transition to university in the people of China, Journal of Adolescence Research, 15, 123-144

[5] Gall, T. L., Evans, D. R., \& Bellerose, S. (2000). Transition to first year university: Patterns of change in adjustment 
across life domains and time. Journal of Social and Clinical Psychology, 19(4), 544-567

[6] Giacobbi, P., Tuccitto, D., Frye, N., 2007, Exercise, affect and university student's appraisals of academic events prior to the final examination period, Psychology of Sport and Exercise, 8, 261-274

[7] Ming -hui, Li, 2008, Helping college students cope: identifying predictors of active coping in different stressful situations, Journal of Psychiatry, Psychology and Mental Health, 2(1), $1-15$.

[8] Kariv, D., Heiman, T., 2005, Task oriented versus emotion-oriented coping strategies: the case of college students, College Student Journal, 39, 72-84

[9] Moller, N., McCarthy, C., Fouladi, R., 2002, Earned attachment security: its relationship to coping resources and stress symptoms among college students following relationship break up, Journal of College Students Development, 43, 213-230

[10] Misra, R., McKean, M., 2000, College students' academic stress and its relationship to their anxiety, time management and leisure satisfaction, American Journal of Health Studies, 16(1), 41-51

[11] Makrides, L., Veinot, P., Richard, J., McKee, E., Gallivan, T., 1998, A cardiovascular health needs assessment of university students living in residence, Canadian Journal of Public Health, 89(3), 171-175

[12] Polychronopoulou, A., Divaris, K., 2005, Perceived sources of stress among Greek dental students, Journal of Dental Education, 69(6), 687-692

[13] Campbell, R.L., Svenson, L.W., Jarvis, G.K., 1992, Perceived level of stress among university undergraduate students in Edmonton, Canada, Perceptual \& Motor Skills, $75(2), 552-554$

[14] Smith, T., Renk, K, 2007, Predictors of academic related stress in college students: An examination of coping, social support, parenting and anxiety, NASPA Journal, 44(3), 405-431

[15] Brougham, R., Zail, C., Mendoza, C., Milelr, J., 2009, Stress, sex differences and coping strategies among college students, Current Psychology, 28(2), 85-97

[16] Padlina, O., Aubert, L., Gehring, T., Martin-Diener, E., Sonaini, B, 2001, Stages of change for perceived stress in a Swiss population: An explorative study, Soz-Praventivmed, 46, 396-403

[17] Velicer, W. F., Prochaska, J. O., Fava, J. L., Norman, G. L., Redding, C. A., 1998, Smoking cessation and stress management: Applications of the transtheoretical model of behavior change, Homeostasis, 38, 216-233

[18] Prochaska, J., Velicer, W., Rossi, J., Goldstein, M., Marcus, B., Rakowski, W., Fiore, C., Harlow, L., Redding, C., Rosenbloom, D., 1994, Stages of change and decisional balance fro 12 problem behaviours, Health Psychology, 13, 39-46

[19] Prochaska, J., Velicer, W, 1997, The transtheoretical model of health behaviour change, American Journal of Health Promotion, 12, 34-48

[20] Laforge, R. G., Velicer, W. F., Richmond, R.L., Owen, N.,
1999, Stage distributions for five health behaviors in the United States and Australia, Preventive Medicine, 28, 61-74

[21] Riley, T., Toth, J., Fava, J., 2000, The transtheoretical model and stress management practices in women at risk for, or inflected with, HIV, Journal of Nursing Care, 11(1), 67-77

[22] Evers, K., Prochaska, J., Johnson, J., Mauriello, L., Padula, J., Procjaska, J., 2006, A randomized clinical trial of a population and transtheoretical model based stress management intervention, Health Psychology, 25, 521-529

[23] Riley, T., Lewis, B., Lewis, M., Fava, J., 2008, Low-income HIV- infected women and the process of engaging in healthy behaviour, Journal of the Association of Nurses in AIDS Care, 19(1), 3-15

[24] P., Burbank, D., Riebe, 2002, Promoting exercise behavior change in older adults: Interventions with Transtheoretical Model, Springer Publishing Company

[25] Godin, G., Shephard, R.J., 1985, A simple method to assess exercise behavior in the community, Canadian Journal of Applied Sport Sciences, 10, 141-146

[26] Woods, C., Mutrie, N., Scott, M., 2002, Physical activity intervention; a transtheoretical model based intervention designed to help sedentary young adults become active, Health Education Research, 17(4), 451-460

[27] Fahrenwald, N., Walker, S., 2003, Application of the transtheoretical model of behaviour change to the physical activity behaviour of WIC mothers, Public Health Nursing, 20(4), 307-317

[28] Mo, J., Betts, N., Horacek, T., Georgiou, C., White, A., 2003, Assessing stages of change for fruit and vegetable intake in young adults: a combination of traditional staging algorithms and food frequency questionnaires, Health Education Research, 18(2), 224-236

[29] Krummel, D., Semmens, E., Boury, J., Gordon, P., Larkin, K., 2004, Stages of change for weight management in postpartum women, Journal of the American Dietetic Association, 104(7), 1102, 1108

[30] Fallon, A., Hausenblas, H., Nigg, C., 2005, The transtheoretical model and exercise adherence: examining constructs associations in later stages of change Psychology of Sport and Exercise, 6, 629-641

[31] Bandura, A., 1977), Self-efficacy: Toward a unifying theory of behavioural change, Psychological Review, 84, 191-215

[32] Bandura, A., 1992, Self-efficacy mechanism in human agency, American Psychologist, 37, 122-147

[33] Velicer, W. F., DiClemente, C. C., Rossi, J. S., Prochaska, J. O., 1990, Relapse situations and self-efficacy: An integrative model, Addictive Behaviors, 15, 271-283

[34] Marcus, H., Rakowski, W., Rossi, S., 1992), Assessing motivational readiness and decision making for exercise, Health Psychology, 11, 257-261

[35] Owen, N., Wakefielf, M., Roberts, L., Esterman, A., 1992, Stages of readiness to quit smoking: Population prevalence and correlate, Health Psychology, 11(6), 413-417

[36] R., Schwarzer, 1993, Measurement of perceived self-efficacy: psychometric scales for cross-cultural research, Berlin: Free 


\section{University Press}

[37] Fava, J., Norman J., Levesque, A., 1998, Measuring decisional balance for stress management, Paper presented in the 19th Annual Scientific Sessions of the Society of Behavioral Medicine, New Orleans

[38] Dye, G., Redding C., Fava, J., Rossi, J., Robbins, M., Meir, K., Velicer, W., Prochaska, L., 2007, Validation of decisional balance, self-efficacy, Rhode Island stress and coping and family support measures for stress management in parents, Paper presented in the 28th Annual Meeting and Scientific Sessions "Science to Impact: The Breadth of Behavioral Medicine". Washington, DC

[39] R., Schwarzer, M., Jerusalem, 1995, Generalized Self-Efficacy scale. In J. Weinman, S., Wright, M., Johnston, Measures in health psychology: A user's portfolio. Causal and control beliefs (pp. 35- 37), Windsor, England: NFER-NELSON

[40] Kamtsios, S., Fylaktakidou A., 2008, The relation between coping strategies, self-efficacy and physical activity participation as revealed through a study held among Ioannina University students, Inquires in Sport and Physical Education, 6(3), 303-310

[41] Cronbach, L.J., 1951, Coefficient alpha and the internal struture of tests, Psychometrika, 16, 297- 334

[42] Gollwitzer, M., 1999, Implementation intentions: Strong effects of simple plans, American Psychologist, 54, 496-503

[43] Dwyer, A. L., Cummings, A. L., 2001, Stress, self-efficacy, social support and coping strategies in university students, Canadian Journal of Counseling, 35(3), 208-220
[44] Williams, K., McGillicubby, A., 2000, Coping strategies in adolescents, Journal of Applied Developmental Psychology, 20(4), 537-549

[45] Hampel, P., Peterman, F., 2005, Age and gender effects on coping in children and adolescents, Journal of Youth and Adolescent, 34(2), 73-83

[46] Hatzigeorgiadis, A., Bibble, S., 2000, Assessing cognitive interference in sport: Development of the thought occurrence questionnaire for sport, Anxiety, Stress and Coping, 13, $65-86$

[47] Sarkin, J., Johnson, S., Prochaska, J.O., Prochaska, L.M., 2001, Applying the transtheoretical model to refular moderate exercise in an overweight population: validation of a stages of change measure, Preventive Medicine, 33(5), 462-469

[48] D., Schunk, F., Pajares, 2002, The development of academic self-efficacy, In A., Wigfield, J., Eccles (Eds.), Development of achievement motivation. San Diego:Academic Press

[49] Papaioannou, A., Bebetsos, E., Kafetzi, S., Sagovitch, A., 2006, Preliminary investigation of a questionnaire based on the model of stages and processes of change towards exercise and physical activity, Inquires in Sport and Physical Education, 4(1), 78-86.

${ }^{1}$ The sample of the present study comes from a bigger one consisted of five hundred and seven (507) students. However, two hundred and nine students (209) reported academic issues as the most stressful situations. 